\title{
Liposarcoma suprarrenal derecho
}

\author{
Right adrenal liposarcoma
}

Nicolás Tarigo-Casella, Martín Vallverdú-Scorza, Daniel Yianssen y Roberto Valiñas-Sotelo

Sanatorio Americano, Montevideo, Uruguay.

Recibido el 6 de noviembre de 2017 y aceptado para publicación el $15 \mathrm{~d}$ noviembre de 2017

Correspondencia a: Dr. Nicolás Tarigo C ntarigo@gmail.com
Hombre de 70 años con tumoración en flanco derecho y sensación de ocupación a dicho nivel, constatándose al examen físico paciente con buen estado general, y ocupación a nivel de flanco derecho por una tumoración de unos $10 \mathrm{~cm}$ de diámetro, indolora.

Se solicitó tomografía computada (Figura 1) y

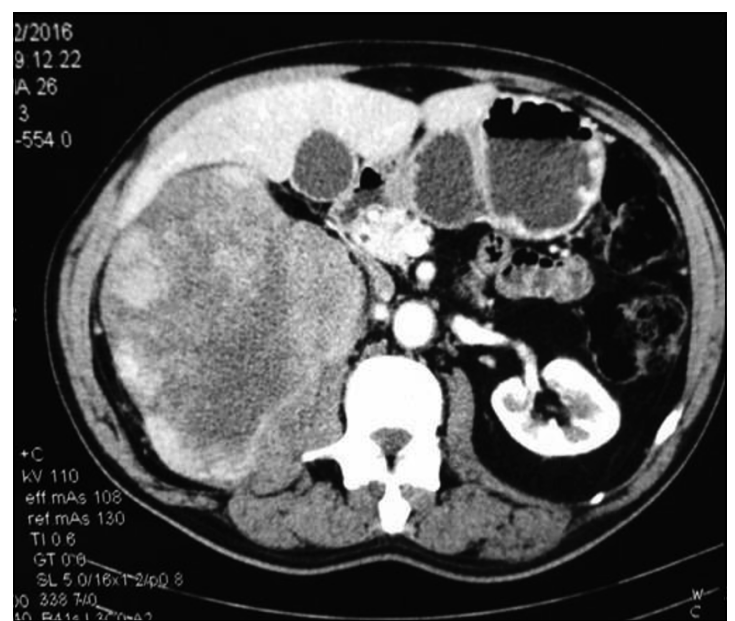

Figura 1. resonancia magnética (Figura 2) evidenciando tumoración vinculada a la glándula suprarrenal derecha.

Se realizó laparotomía mediante incisión transversa de flanco derecho con extensión a izquierda, resección quirúrgica del riñón derecho y suprarrenal derecha (Figuras 3 y 4 ).

El paciente evolucionó en forma favorable.

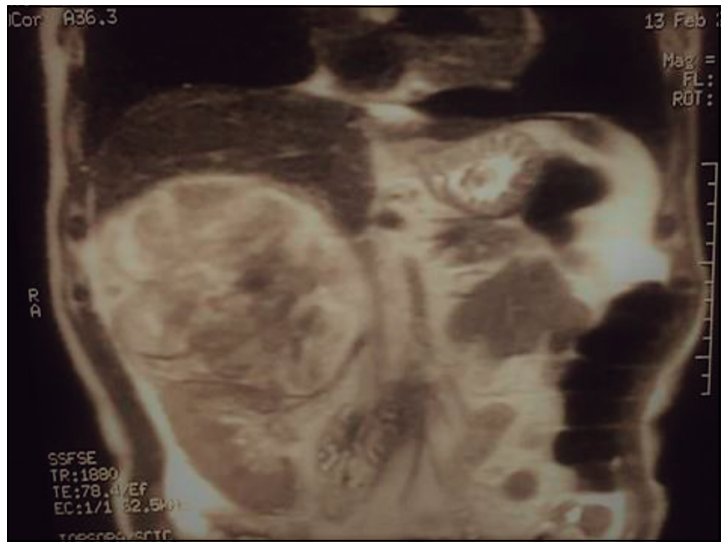

Figura 2.

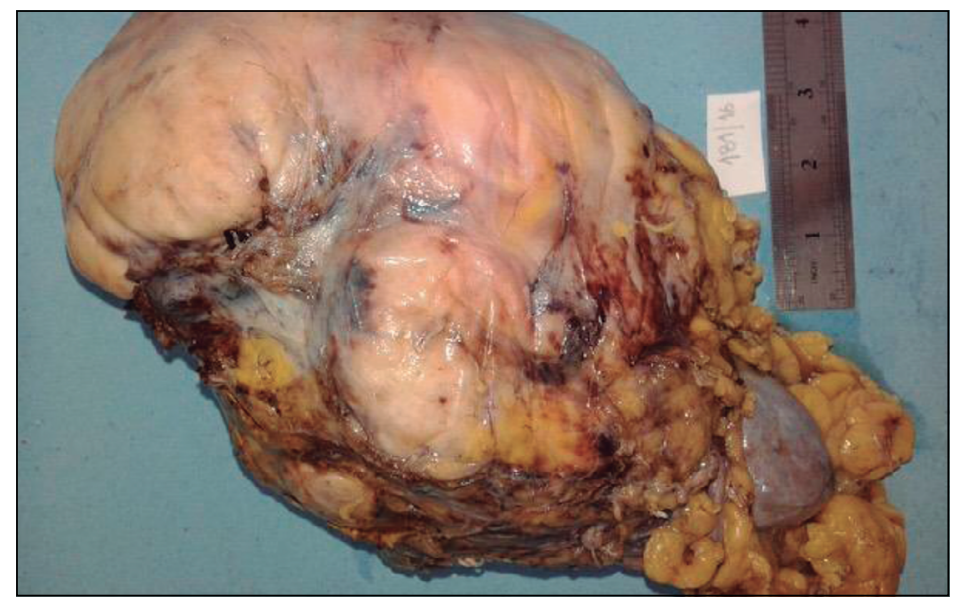

Figura 3. 
La anatomía patológica informó liposarcoma suprarrenal derecho, márgenes de sección libres de tumor.

\section{Responsabilidades éticas}

Protección de personas y animales. Los autores declaran que para esta investigación no se han realizado experimentos en seres humanos ni en animales.

Confidencialidad de los datos. Los autores declaran que han seguido los protocolos de su centro de trabajo sobre la publicación de datos de pacientes.

Derecho a la privacidad y consentimiento informado. Los autores declaran que en este artículo no aparecen datos de pacientes.

Conflictos e interés: No hay.

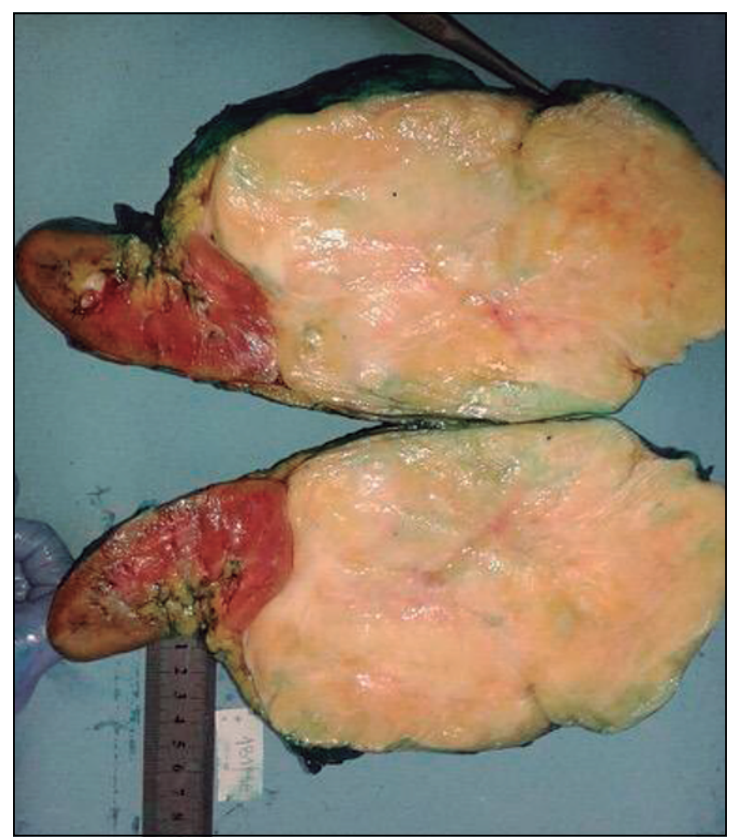

Figura 4.

\section{Bibliografía}

1. Yoo JY, McCoy KL, Carty SE, Stang MT, Armstrong MJ, Howell GM, et al. Adrenal Imaging Features Predict Malignancy Better than Tumor Size. Ann Surg Oncol. 2015;22:721-7.

2. Vajtai Z, Karngold E, Hooper JE, Sheppard BC, Foster BR, Coakley FV. Suprarrenal retroperitoneal Liposarcoma with intracaval tumor thrombus: an imaging mimic of adrenocortical carcinoma. Clinical Imaging 2014; 38:75-7.

3. Lockhart ME, Smith JK, Kenney FJ. Imaging of adrenal masses. European Journal of Radiology 2002;41:95-112. 